\title{
Thermal stability, traction and tribofilm formation of three fatty acid-derived \\ ionic liquids
}

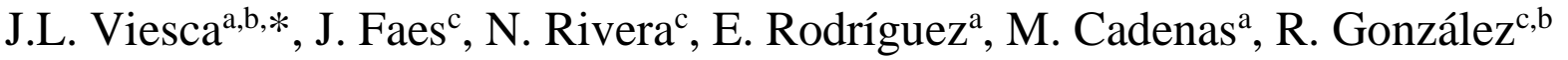 \\ ${ }^{\text {a }}$ Department of Construction and Manufacturing Engineering, University of Oviedo, Asturias, Spain \\ ${ }^{\mathrm{b}}$ Faculty of Science and Technology, Bournemouth University, UK \\ ${ }^{c}$ Department of Marine Science and Technology, University of Oviedo, Asturias, Spain \\ (*) Email: viescajose@ uniovi.es / Orcid ID: 0000-0002-9838-8634
}

\section{Abstract}

This work reports thermal stability, traction and tribofilm formation properties of three fatty acid-derived ionic liquids (FAILs) and evaluates the influence of the chemical structure of the anion on the properties indicated above. The results indicated that thermal stability of the FAILs is related with the chemical structure of the anion (longer alkyl chain length increases thermal stability and the presence of double bond decreases it). At high temperatures and low speeds, the $\left[\mathrm{N}_{8,8,8,1}\right]\left[\mathrm{C}_{6: 0}\right]$ led to the lowest traction values and the $\left[\mathrm{N}_{8,8,8,1}\right]\left[\mathrm{C}_{18: 1}\right]$ had the highest ones. All FAILs reacted with the steel surfaces creating a tribofilm, that increased with time.

Keywords: fatty acid; ionic liquids; thermal stability; lubrication; friction

\section{1.- Introduction}

Ionic liquids (IL) are defined as salts whose melting point is below $100^{\circ} \mathrm{C}$. In general, ILs have great thermal stability, very low flammability and practically no volatility. For this reason, ILs have been used in numerous fields of application [1, 2]. However, the first scientific work that reported the use of ILs as lubricant dates back to 2001 [3]. Since then, scientific interest in ILs in the field of lubrication has grown enormously [4-7] and numerous papers have been published showing that ILs have very good lubricating properties. Some authors have reported that the 
1 mechanisms of action of ILs in lubrication are associated to their ability to react with the lubricated

2 surfaces forming tribolfims, which reduce friction and/or wear [8-21].

Currently, lubricants require more than good tribological behavior and they must be able

4 to minimize their impact on the natural environment [22]. For this reason, novel ILs are being

5 synthesized free of halogens, aromatic groups or metals in their chemical structure. One approach

6 in this direction has been the synthesis of ionic liquids from natural sources, which include the use

7 of natural fatty acids. The ionic liquids studied in this work were synthesized using this approach,

8 resulting in a low toxicity and a moderate biodegradability [23].

In previous works, ILs with anions derived from fatty acids were used as pure lubricant or as additive in a synthetic oil (ester) [24-27] leading to the formation of tribofilms on the steel surfaces of the tribological pairs. Furthermore, the values of friction coefficient and wear were reduced $60 \%$ and $28 \%$, respectively, when the ester was additised with 2 wt. $\%$ of the IL [25] and up to $65 \%$ and $33 \%$, respectively, when ionic liquids were used as pure lubricants [27].

The current work studies the lubricating behavior (tribofilm formation and traction coefficient versus mean entrainment speed curves) of three hexanoate-, stearate- and oleate anionbased ILs. In addition, their thermal stability was studied in order to complement previous physicochemical (viscosity, density, miscibility, wettability) and environmental characterizations (biodegradability and toxicity) [23, 28]. The main goal of the work is to have a complete characterization of these ionic liquids in order to be used as more environmentally friendly lubricants and to evaluate the influence of the different chemical structures of the anion on the analyzed properties. 


\section{$1 \quad$ 2.- Experimental details}

2 2.1.- Ionic liquids

Methyltrioctylammonium hexanoate $\left(\left[\mathrm{N}_{8,8,8,1}\right]\left[\mathrm{C}_{6: 0}\right]\right)$, methyltrioctylammonium stearate

$4\left(\left[\mathrm{~N}_{8,8,8,1}\right]\left[\mathrm{C}_{18: 0}\right]\right)$ and methyltrioctylammonium oleate $\left(\left[\mathrm{N}_{8,8,8,1}\right]\left[\mathrm{C}_{18: 1}\right]\right)$ fatty acid derived ILs (Fig.

5 1) were synthesized employing a salt metathesis reaction, following the method described in a

6 previous authors's work [25]. The molecular structures of the synthesized FAILs were confirmed

7 by FTIR and ${ }^{1} \mathrm{H}$ and ${ }^{13} \mathrm{C}$ NMR analysis [28].

For the synthesis, different reagents (supplied by Sigma-Aldrich S.A.) have been employed

9 such as methyltrioctylammonium bromide ionic liquid $\left(\left[\mathrm{N}_{8,8,8,1}\right][\mathrm{Br}]\right)(\geq 97 \%)$ as cation precursor;

10 hexanoic, stearic and oleic acids (natural $\geq 95 \%$ ) as anion precursors; sodium hydroxide, ethanol

11 solution $(70 \% \mathrm{w} / \mathrm{w})$ and toluene $(99.8 \%)$.

12

Methyltrioctylammonium hexanoate $\left(\left[\mathrm{N}_{8,8,8,1}\right]\left[\mathrm{C}_{6: 0}\right]\right)$

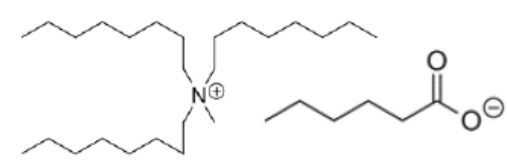

Methyltrioctylammonium stearate $\left(\left[\mathrm{N}_{8,8,8,1}\right]\left[\mathrm{C}_{18: 0}\right]\right)$

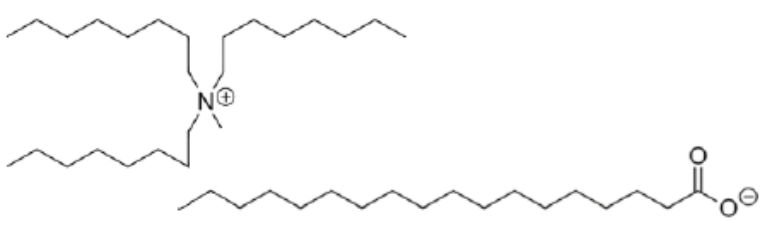

Methyltrioctylammonium oleate $\left(\left[\mathrm{N}_{8,8,8,1}\right]\left[\mathrm{C}_{18: 1}\right]\right)$.

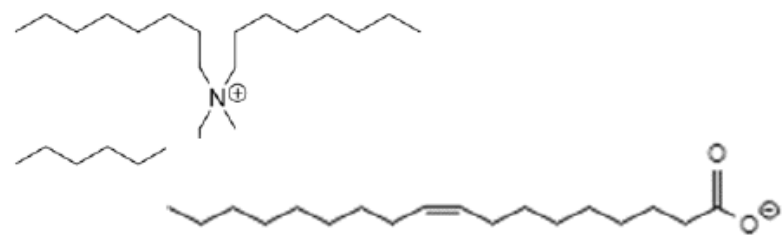

Figure 1. Names, abbreviations and chemical structures of the FAILs. 
2.2.- Thermal stability 4 FAILs.

A DSC/SDT Q600 thermogravimetric analyzer (TGA) and differential scanning calorimeter (DSC) from TA Instruments was employed to determined thermal stability of the

A sample of approximately $6 \mathrm{mg}$ of each FAIL was used, a heating rate of $10^{\circ} \mathrm{C} / \mathrm{min}$ was used, heating the sample from room temperature to $600{ }^{\circ} \mathrm{C}$. The analysis was carried out in an oxygen atmosphere and a flux of $50 \mathrm{~mL} / \mathrm{min}$.

\section{3.- Tribological tests}

For the study of tribofilm formation and traction properties of the new synthesized FAILs, two different tests were developed in a Mini Traction Machine (MTM) tribometer from PCS Instruments (see scheme in Fig. 2), with a ball-on-disc configuration. Steel balls of $19.05 \mathrm{~mm}$ (3/4") diameter (AISI 52100, hardness 820-920 HV and surface roughness Ra $<0.02 \mu \mathrm{m}$ ) and 40 mm-diameter steel disc (AISI 52100, hardness 720-780 HV and surface roughness $\mathrm{Ra}<0.02 \mu \mathrm{m}$ ) were employed in both tests.
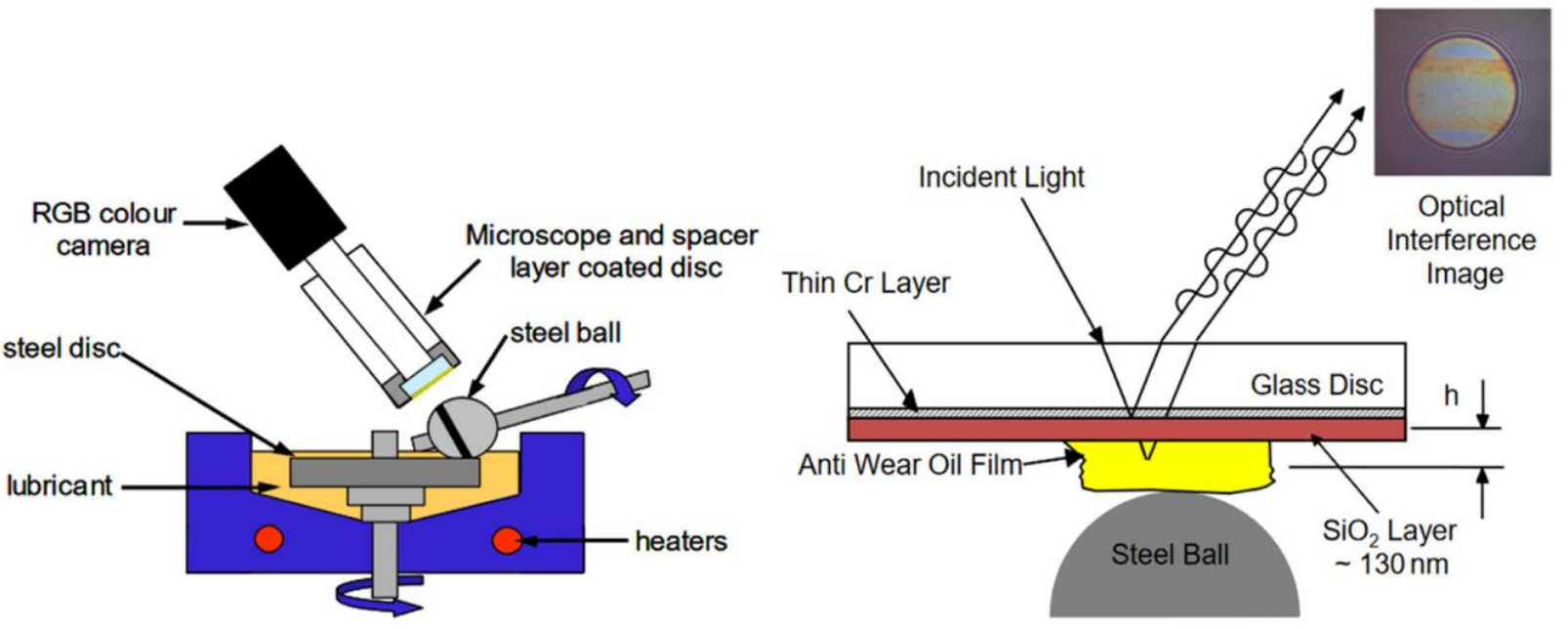

Figure 2. Scheme of Mini-Traction Machine (Courtesy from PCS Instruments). Left: Ball-ondisk set-up; Right: Tribolayer measurement configuration. 
Firstly, traction coefficient under different lubrication regimes was determined. The tests

2 were performed with a volume of $10 \mathrm{~mL}$ of the corresponding FAIL lubricating the contact, a

3 sliding rolling ratio (SSR) of $50 \%$, temperatures of $40,60,80$ and $100{ }^{\circ} \mathrm{C}$, and at $30 \mathrm{~N}$-load

4 (equivalent to a mean contact pressure of $0.64 \mathrm{GPa}$ ). Main entrainment speed was varied between

52000 and $10 \mathrm{~mm} / \mathrm{s}$. Considering $u_{b}$ and $u_{d}$ as the ball and disc speeds at the contact point,

6 respectively, the mean entrainment speed was calculated as $\left(u_{b}+u_{d}\right) / 2$, while SRR was determined

7 as the ratio sliding speed/mean speed, being $u_{d}-u_{b}$ the sliding speed. The electrical contact

8 resistance (ECR) was also recorded during the tests.

9 Secondly, tests were made under rolling/sliding motion conditions in order to determine

10 the capacity of the three FAILs of forming protective surface tribofilm. For this purpose, Mini

11 Traction Machine was equipped with a 3D spacer layer imaging to determine the formation of

12 tribofilms on the ball's surfaces during tests by means of optical interferometry. In this case, 60-

$13 \mathrm{~min}$ tests were developed at $50-\mathrm{N}$ load ( $0.75 \mathrm{GPa}$ of mean contact pressure), $100^{\circ} \mathrm{C}$ of temperature,

$1450 \%$ of SSR, $150 \mathrm{~mm} / \mathrm{s}$ of mean entrainment speed and using a sample volume of $10 \mathrm{~mL}$. Tests

15 were periodically paused, and the steel ball was placed against a disc of glass layered with silica 16 and chromium and illuminated by a white light source. That allows to obtain an interference image 17 that could be recorded and analyzed in order to measure the thickness of the tribofilm created.

18 Before both tests petroleum ether was used in order to clean specimens in a 10 minutes 19 ultrasonic bath, later they were washed with ethanol and dried by hot air.

\section{3.- Results and discussion}

22 3.1.- Thermal stability

23 Figure 3 presents the thermal degradation of the three investigated FAILs. As can be seen, 24 their thermal stability does not differ too much and all of them are completely degraded (mass loss $25>90 \%$ ) at temperatures lower than $300{ }^{\circ} \mathrm{C}$. At low temperatures, even below $100{ }^{\circ} \mathrm{C}$, the three 
1 ionic liquids experience a certain loss of mass, which is more evident in the case of $\left[\mathrm{N}_{8,8,8,1}\right]\left[\mathrm{C}_{18: 1}\right]$.

2 However, this does not represent a true decomposition of the FAILs, rather it is the result of water

3 evaporation and decomposition of volatile material from reagents used and the proper synthesis 4 process [29, 30].

Table 1 shows the initial decomposition temperature ( $\left.\mathrm{T}_{\text {onset }}\right)$ of the FAILs, determined as the point of intersection of the starting-mass baseline and the tangent to the TGA curve at the point of maximum slope; the different mass loss temperatures $\left(\mathrm{T}_{10 \%}, \mathrm{~T}_{20 \%}\right.$ and $\left.\mathrm{T}_{50 \%}\right)$; and the final degradation temperature $\left(\mathrm{T}_{\text {offset }}\right)$ determined as the point of intersection of the final-mass baseline and the tangent to the TGA curve at the point of maximum slope.

Analyzing the influence of the length of the alkyl chain of the anion on thermal stability of the ionic liquids, it is observed that the $\mathrm{T}_{\text {onset }}$ is $190.4{ }^{\circ} \mathrm{C}$ for the FAIL with the longest chain $\left(\left[\mathrm{N}_{8,8,8,1}\right]\left[\mathrm{C}_{18: 0}\right]\right)$ and the FAIL with the shortest chain $\left(\left[\mathrm{N}_{8,8,8,1}\right]\left[\mathrm{C}_{6: 0}\right]\right)$ has a $\mathrm{T}_{\text {onset }}$ of $179.6^{\circ} \mathrm{C}$. This difference is maintained as temperature increases; thus, the temperature for a mass loss of $50 \%$ is $221.6^{\circ} \mathrm{C}$ and $204.6^{\circ} \mathrm{C}$, respectively. This conclusion agrees with the results obtained in a previous work [31], where thermal stability of other two FAILs $\left(\left[\mathrm{N}_{6,6,6,6}\right]\left[\mathrm{C}_{16: 0}\right]\right.$ and $\left.\left[\mathrm{N}_{6,6,6.6}\right]\left[\mathrm{C}_{8: 0}\right]\right)$ was determined. Nonetheless, it was not possible to find a clear relationship between thermal stability and the length of the alkyl chain of the anion in other research works [26, 27].

On the other hand, the $\mathrm{T}_{\text {onset }}$ of the FAILs $\left[\mathrm{N}_{6,6,6,6}\right]\left[\mathrm{C}_{16: 0}\right]$ and $\left[\mathrm{N}_{6,6,6,6}\right]\left[\mathrm{C}_{8: 0}\right]$ was between 167 and $176^{\circ} \mathrm{C}$ [31]. These values are below those obtained for the ILs analyzed in this work. On the contrary, traditional ionic liquids (not synthesized from fatty acids) have higher $\mathrm{T}_{\text {onset }}$ values $[25,32]$. It should be noted that, in these cases, the different thermal stability of ionic liquids not only depends on the different chemical structures of the anion, but also of the cation [33-35]. 


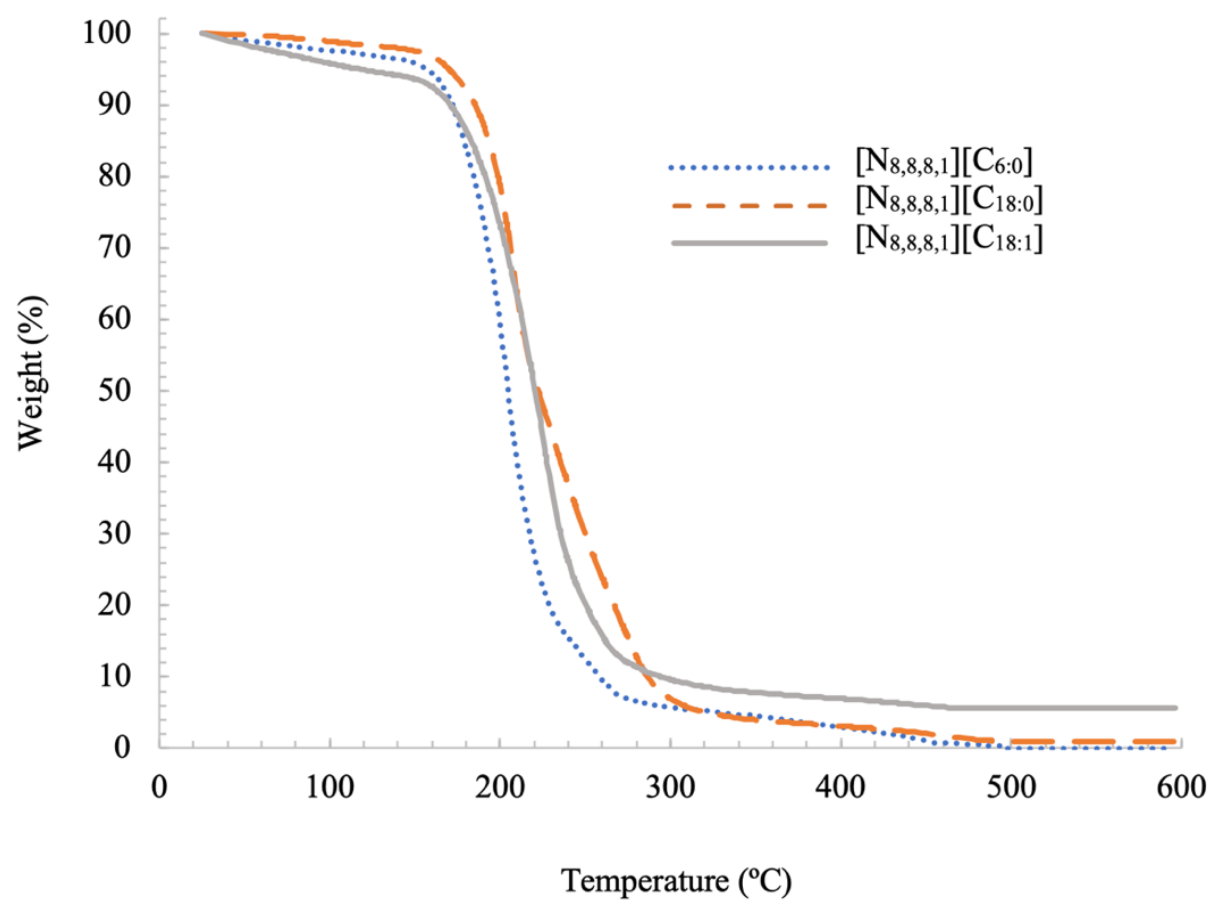

Figure 3. Thermal analysis of the FAILs (atmosphere: $\mathrm{O}_{2}$ ).

Analyzing the effect of the double bond in the chemical structure of the anion in the FAIL

$14\left[\mathrm{~N}_{8,8,8,1}\right]\left[\mathrm{C}_{18: 1}\right]$, its $\mathrm{T}_{\text {onset }}, \mathrm{T}_{10 \%}, \mathrm{~T}_{20 \%}, \mathrm{~T}_{50 \%}$ and $\mathrm{T}_{\text {offset }}$ were lower than that of the FAIL without

15 double bond and the same alkyl chain length $\left(\left[\mathrm{N}_{8,8,8,1}\right]\left[\mathrm{C}_{18: 0}\right]\right)$. The presence of double bond

16 decreases the thermal stability of the FAIL. Analyzing the TGA curve (Fig. 3) at high temperatures 17 (even at $600{ }^{\circ} \mathrm{C}$ ) it is observed that the $\left[\mathrm{N}_{8,8,8,1}\right]\left[\mathrm{C}_{18: 1}\right]$ FAIL is not completely degraded. This is

18 probably due to the presence of metallic impurities (arsenic, cadmium and mercury) in the anion

19 precursor used in the formulation of the $\left[\mathrm{N}_{8,8,8,1}\right]\left[\mathrm{C}_{18: 1}\right] \mathrm{FAIL}$, which are not degraded and remain

20 forming ashes.

Table 1: Decomposition temperature of the ionic liquids.

\begin{tabular}{cccccc}
\hline & $\mathrm{T}_{\text {onset }}\left({ }^{\circ} \mathrm{C}\right)$ & $\mathrm{T}_{10 \%}\left({ }^{\circ} \mathrm{C}\right)$ & $\mathrm{T}_{20 \%}\left({ }^{\circ} \mathrm{C}\right)$ & $\mathrm{T}_{50 \%}\left({ }^{\circ} \mathrm{C}\right)$ & $\mathrm{T}_{\text {offset }}\left({ }^{\circ} \mathrm{C}\right)$ \\
\hline$\left[\mathrm{N}_{8,8,8,1}\right]\left[\mathrm{C}_{6: 0}\right]$ & 179.6 & 171.9 & 187.4 & 204.6 & 232.1 \\
{$\left[\mathrm{~N}_{8,8,8,1}\right]\left[\mathrm{C}_{18: 0}\right]$} & 190.4 & 183.3 & 198.1 & 221.6 & 258.9 \\
{$\left[\mathrm{~N}_{8,8,8,1}\right]\left[\mathrm{C}_{18: 1}\right]$} & 181.3 & 170.3 & 190.0 & 220.5 & 253.7 \\
\hline
\end{tabular}


Figure 4 shows traction coefficient values versus mean entrainment speed (Stribeck curves) of the three FAILs at 40, 60, 80 and $100{ }^{\circ} \mathrm{C}$. As can be observed, all the FAILs exhibited similar behavior for the lowest temperature tested $\left(40{ }^{\circ} \mathrm{C}\right)$, with low traction coefficient values even at low speeds, where the higher viscosity of the ILs at that temperature allow sufficient thickness of lubricant film to achieve a separation of the surfaces preventing metal-metal contact.

The $\left[\mathrm{N}_{8,8,8,1}\right]\left[\mathrm{C}_{6: 0}\right]$ and $\left[\mathrm{N}_{8,8,8,1}\right]\left[\mathrm{C}_{18: 0}\right]$ exhibited similar traction coefficient values at $60{ }^{\circ} \mathrm{C}$ for all tested speeds, while a different behavior was observed with [ $\left.\mathrm{N}_{8881}\right]\left[\mathrm{C}_{18: 1}\right]$. For this latter IL, higher values of friction at the lower speeds can be observed, not reaching the elastohydrodynamic regime up to $300 \mathrm{~mm} / \mathrm{s}$. While for the other FAILs this regime is achieved at lower speeds. The above results agree with the ECR behavior obtained at that temperature. As can be observed, the $\left[\mathrm{N}_{8,8,8,1}\right]\left[\mathrm{C}_{18: 1}\right]$ shows very low ECR values compared with the other two FAILs, especially at low speeds. The different behavior exhibited for this FAIL compared to $\left[\mathrm{N}_{8,8,8,1}\right]\left[\mathrm{C}_{18: 0}\right]$ could be related to the existence of a double bond in the chemical structure of the anion and its relationship with physical properties, which influence on lubricant behavior.

An increment in the traction coefficient values at lower speeds can be observed as the temperature increases $\left(80\right.$ and $\left.100{ }^{\circ} \mathrm{C}\right)$. These logical results are due to the reduction of the film thickness that occurs with the decrease in viscosity at higher temperatures. All the FAILs also showed the transition between mixed and elastrohydrodynamic lubrication regimes at higher speeds as the temperature increased. This fact was especially noticeable for the $\left[\mathrm{N}_{8,8,8,1}\right]\left[\mathrm{C}_{18: 1}\right]$, exhibiting the highest traction coefficient values at higher temperatures and lower speeds, and reaching the elastohydrodynamic lubrication regime above $500 \mathrm{~mm} / \mathrm{s}$. This may also be influenced by the lower thermal stability of IL at the highest temperatures tested.

Likewise $\left[\mathrm{N}_{8,8,8,1}\right]\left[\mathrm{C}_{6: 0}\right]$ FAIL shows, at the highest temperatures tested, the lowest traction coefficient results, and a transition from mixed to elastohydrodynamic lubrication regime at lower speeds than the observed for the other two ILs, especially with the $\left[\mathrm{N}_{8,8,8,1}\right]\left[\mathrm{C}_{18: 1}\right]$ ones. The highest 
1 values of viscosity reported for this FAIL [23] justified this behavior, specially at the lower speeds

1

22 studied.

4
3 The ECR results at 80 and $100^{\circ} \mathrm{C}$ are according with results in the Stribeck curves. Measured ECR

4 values decrease with increasing temperature, indicating a worsening of the lubrication conditions

5 due to more asperities contact between surfaces. The $\left[\mathrm{N}_{8,8,8,1}\right]\left[\mathrm{C}_{6: 0}\right]$ exhibited the higher ECR 6 values, specially at the higher speeds, while the $\left[\mathrm{N}_{8,8,8,1}\right]\left[\mathrm{C}_{18: 1}\right]$ showed very low ECR values at $7 \quad 100^{\circ} \mathrm{C}$. 
$40^{\circ} \mathrm{C}$
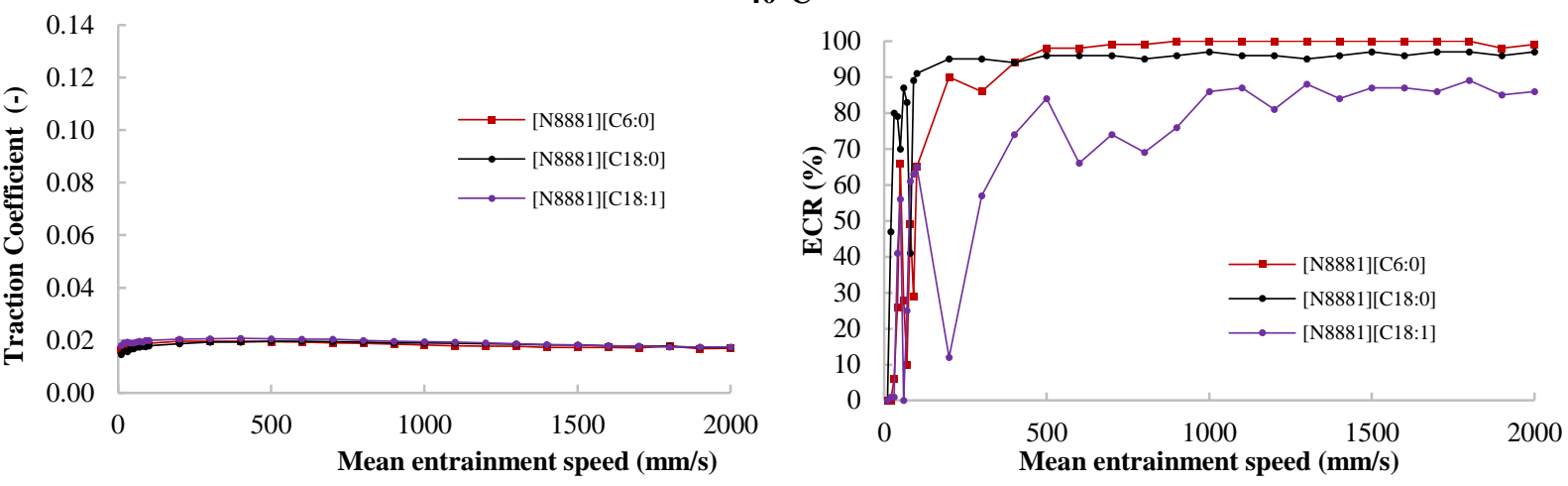

$60^{\circ} \mathrm{C}$
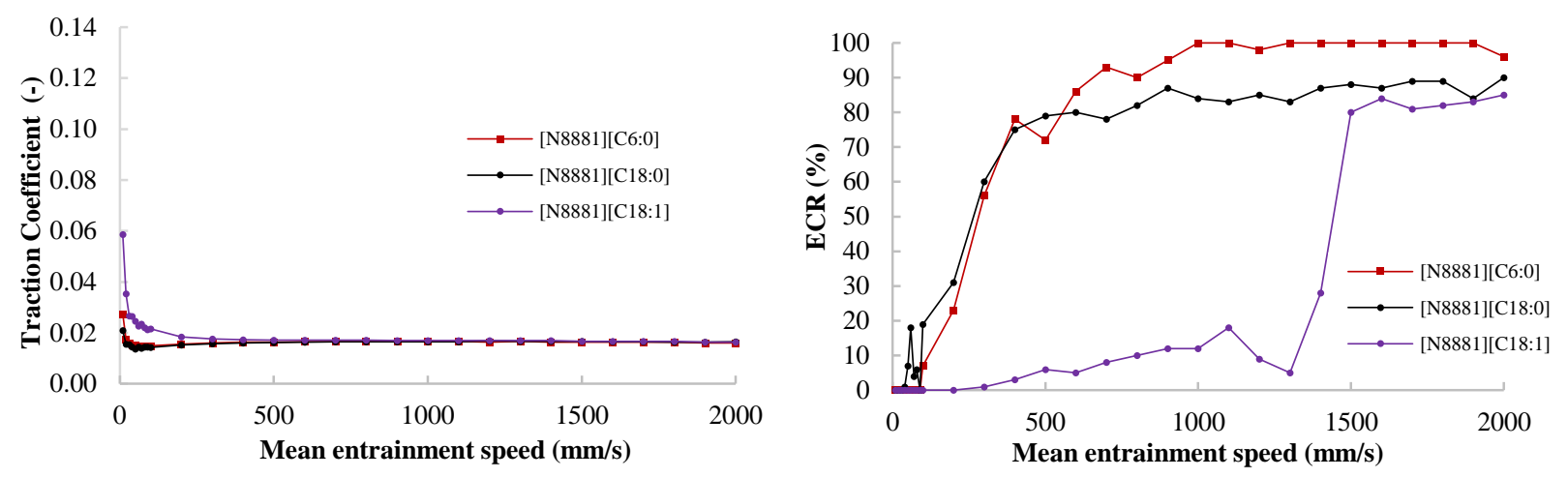

\section{$80^{\circ} \mathrm{C}$}
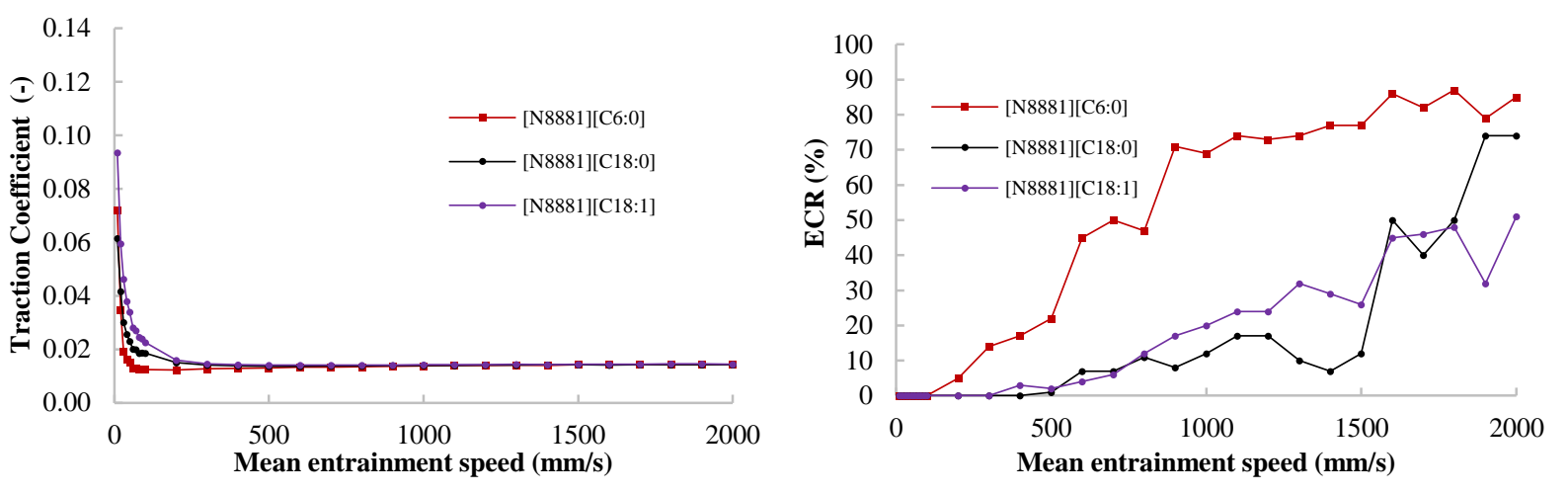

$100^{\circ} \mathrm{C}$
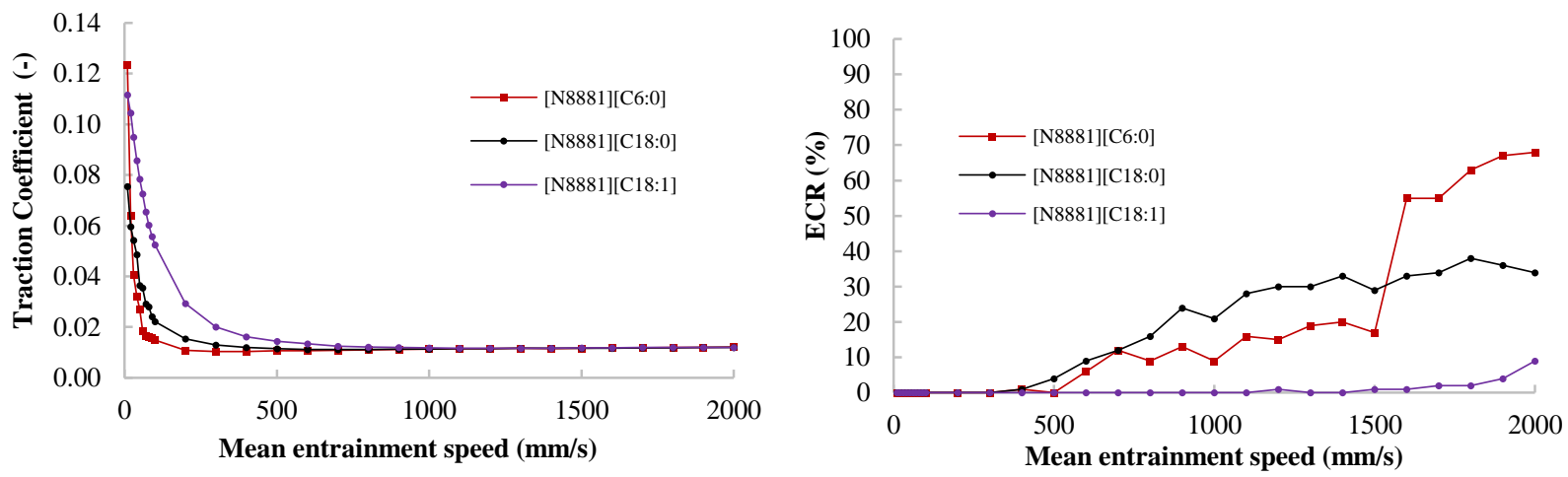

1 Figure 4. Stribeck curves and ECR of the ionic liquids at different temperatures during traction 
3.5.- Tribofilm formation

Figure 5 shows optical interference images during the tribofilm formation in the tests made

3 with the FAILs studied. It can be observed that all the samples reacted with the steel surface,

4 generating a surface tribolayer, which increases with time. This result agrees with a previous work

5 [24], where the formation of chemical tribofilms on steel surfaces lubricated with fatty acid-

6 derived anions was reported. These layers contribute to friction reduction and improve antiwear

7 performance.

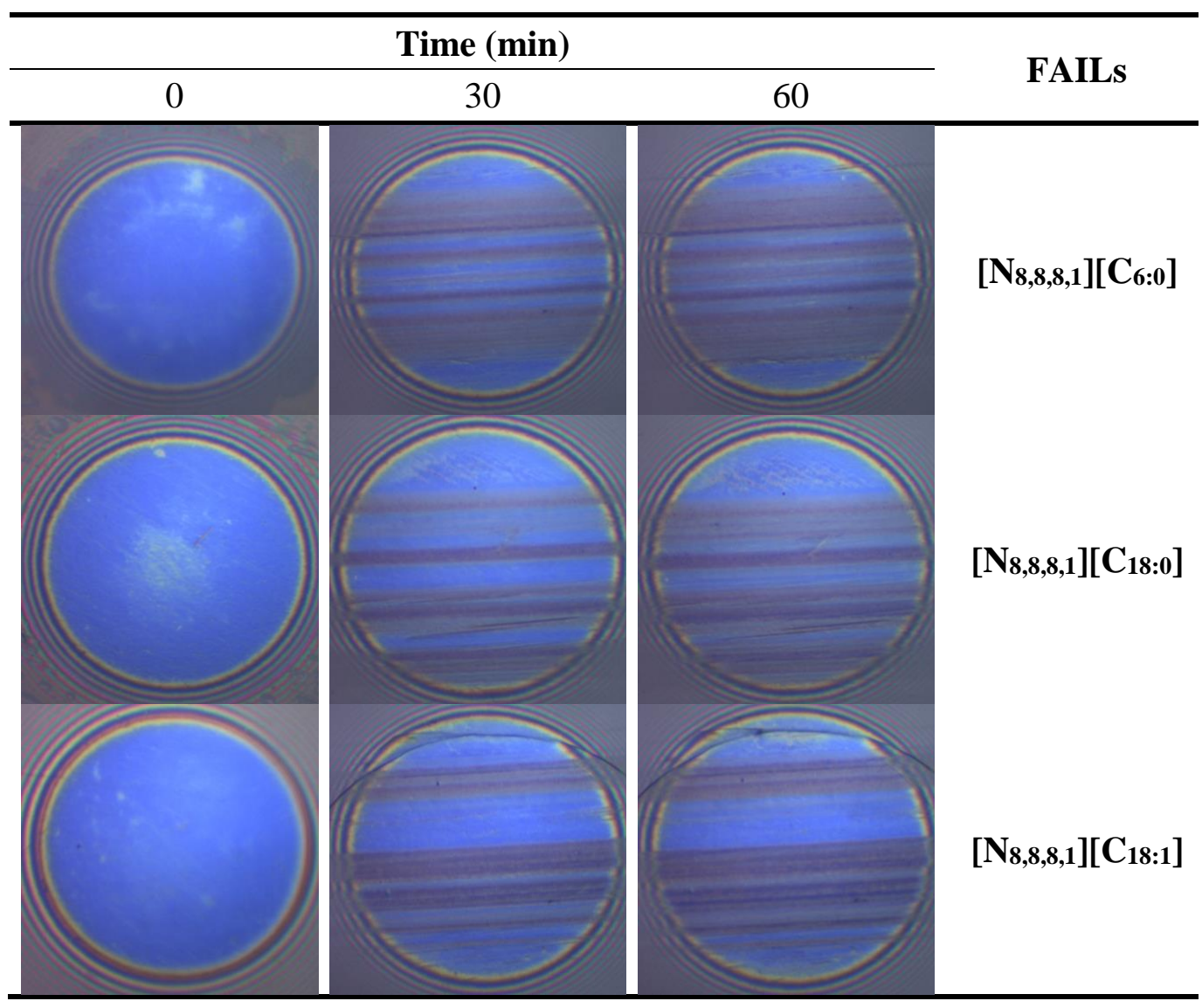

Figure 5. Images taken on the ball surface from the tribofilm formation tests.

The evolution of the thickness of the tribofilms formed during tests versus time is shown in Fig. 6. All the FAILs showed an increasing tribofilm formation with time.

As can be see in Fig. 4 , the $\left[\mathrm{N}_{8,8,8,1}\right]\left[\mathrm{C}_{18: 0}\right]$ and $\left[\mathrm{N}_{8,8,8,1}\right]\left[\mathrm{C}_{18: 1}\right]$ FAILs have higher friction values in the lubrication regimes boundary and mixed than the FAIL with the shortest chain 
1 ([N8,8,8,1][C $\left.\left.\mathrm{C}_{6: 0}\right]\right)$. This worse lubricating behavior could be caused by the lower vistosity of both

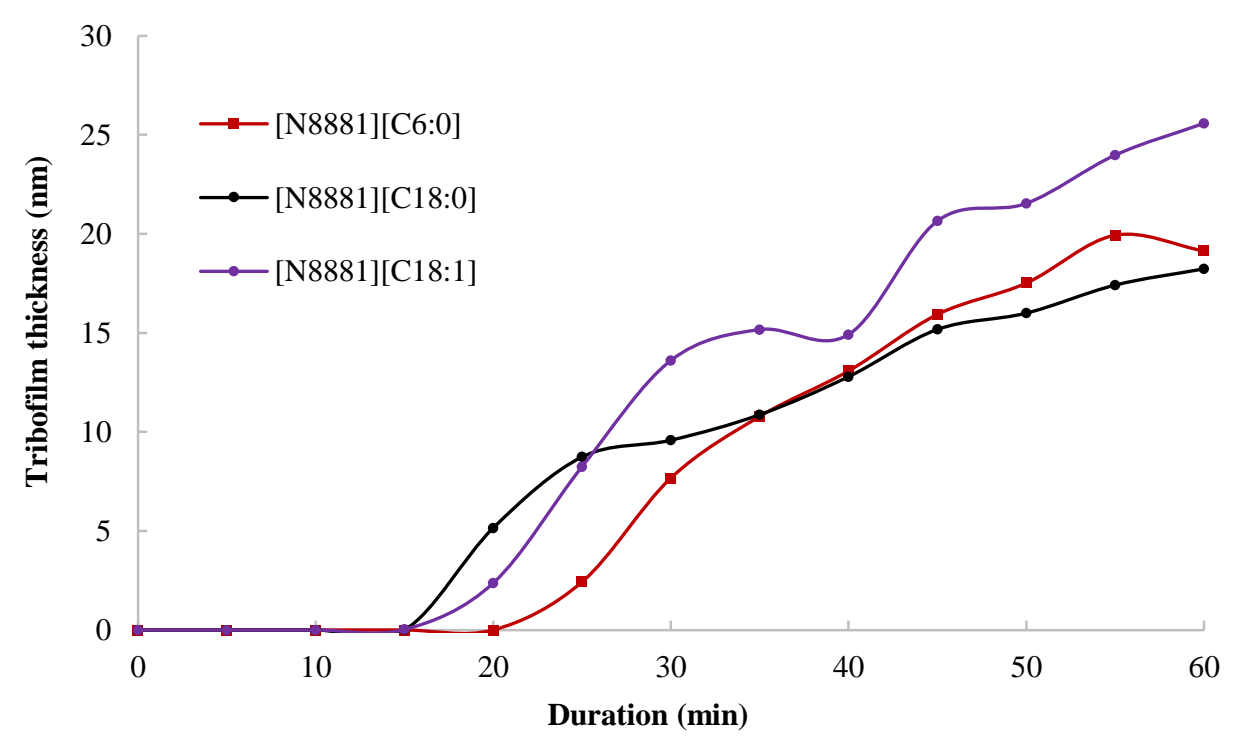

Figure 6. Evolution of tribofilm thickness against time.

\section{4.- Conclusions}

Three hexanoate-, stearate- and oleate anion-based ILs were used in order to study some lubrication properties (traction and tribofilm formation), as well as their thermal stability. The following conclusions were extracted from the obtained results:

- $\left[\mathrm{N}_{8,8,8,1}\right]\left[\mathrm{C}_{6: 0}\right],\left[\mathrm{N}_{8,8,8,1}\right]\left[\mathrm{C}_{18: 0}\right]$ and $\left[\mathrm{N}_{8,8,8,1}\right]\left[\mathrm{C}_{18: 1}\right]$ FAILs show similar thermal stability and all of them are completely degraded (mass loss $>90 \%$ ) at temperatures below 300 ${ }^{\circ} \mathrm{C}$. 
- Thermal stability increased with longer alkyl chain of the anion and it decreased with presence of double bond in the anion. Thus, the $\left[\mathrm{N}_{8,8,8,1}\right]\left[\mathrm{C}_{18: 0}\right]$ had the best thermal stability values.

- $\quad\left[\mathrm{N}_{8,8,8,1}\right]\left[\mathrm{C}_{6: 0}\right]$ and $\left[\mathrm{N}_{8,8,8,1}\right]\left[\mathrm{C}_{18: 0}\right]$ FAILs exhibited similar traction (friction) behavior at 40 and $60^{\circ} \mathrm{C}$. However, $\left[\mathrm{N}_{8,8,8,1}\right]\left[\mathrm{C}_{18: 1}\right]$ showed higher traction values at low speeds as the temperature increases. At high temperatures and low speeds $\left[\mathrm{N}_{8,8,8,1}\right]\left[\mathrm{C}_{6: 0}\right] \mathrm{FAIL}$ showed the lowest traction values.

- All FAILs reacted with the steel surfaces creating a tribofilm that increase it thickness along time. The FAILs with faster reaction with the surface were $\left[\mathrm{N}_{8,8,8,1}\right]\left[\mathrm{C}_{18: 1}\right]$ and $\left[\mathrm{N}_{8,8,8,1}\right]\left[\mathrm{C}_{18: 0}\right]$ and the former led to the thicker tribofilm.

\section{Acknowledgements}

The authors would like to express their gratitude to the Foundation for the Promotion in Asturias of Applied Scientific Research and Technology (FC-GRUPIN-IDI/2018/000131) and to the Spanish Ministry of Economy and Competitiveness (MINECO-17-DPI2016-79690-R) for the financial support under which this research has been carried out.

\section{References}

[1] T. Welton, Room-temperature ionic liquids. Solvents for synthesis and catalysis, Chemical Reviews 99(8) (1999) 2071-2083, https://doi.org/10.1021/cr980032t

[2] N.V. Plechkova, K.R. Seddon, Applications of ionic liquids in the chemical industry, Chemical Society Reviews 37(1) (2008) 123-150, https://doi.org/10.1039/b006677j

[3] C. Ye, W. Liu, Y. Chen, L. Yu, Room-temperature ionic liquids: a novel versatile lubricant, Chem Commun (Camb) (2001) 2244-2245, https://doi.org/10.1039/B106935G. 
1 [4] I. Minami, Ionic liquids in tribology, Molecules 14 (2009) 2286-2305,

2 https://doi.org/10.3390/molecules14062286.

3 [5] M.D. Bermúdez, A.E. Jiménez, J. Sanes, F.J. Carrión, Ionic liquids as advanced lubricant fluids, Molecules 14 (2009) 2888-2908, https://doi.org/10.3390/molecules14082888.

[6] A. Somers, P. Howlett, D. MacFarlane, M. Forsyth, A review of ionic liquid lubricants, Lubricants 1 (2013) 3-21, https://doi.org/10.3390/lubricants 1010003.

[7] Y. Zhou, J. Qu, Ionic liquids as lubricant additives - a review, ACS Appl. Mater. Interfaces 9 (4) (2017) 3209-3222, https://doi.org/10.1021/acsami.6b12489.

[8] J.L. Viesca, M.T. Mallada, D. Blanco, A. Fernández-González, J. Espina-Casado, R. González, A. Hernández Battez, Lubrication performance of an ammonium cation-based ionic liquid used as an additive in a polar oil, Tribology International 116 (2017) 422-430, https://doi.org/10.1016/j.triboint.2017.08.004

[9] I. Otero, E.R. López, M. Reichelt, J. Fernández, Friction and anti-wear properties of two tris(pentafluoroethyl) trifluorophosphate ionic liquids as neat lubricants, Tribol. Int. 70 (2014) 104-111, https://doi.org/10.1016/j.triboint.2013.10.002.

[10] R. González, M. Bartolomé, D. Blanco, J.L. Viesca, A. Fernández-González, A.H. Battez, Effectiveness of phosphonium cation-based ionic liquids as lubricant additive, Tribol. Int. 98 (2016) 82-93, https://doi.org/10.1016/j.triboint.2016.02.016.

[11] A.E. Somers, S.M. Biddulph, P.C. Howlett, J. Sun, D.R. MacFarlane, M. Forsyth, A comparison of phosphorus and fluorine containing IL lubricants for steel on aluminium, Phys. Chem. Chem. Phys. 14 (2012) 8224, https://doi.org/10.1039/c2cp40736a.

[12] A.E. Jiménez, M.D. Bermúdez, Imidazolium ionic liquids as additives of the synthetic ester propylene glycol dioleate in aluminium-steel lubrication, Wear 265 (2008) 787-798, https://doi.org/10.1016/j.wear.2008.01.009.

[13] A.E. Somers, B. Khemchandani, P.C. Howlett, J. Sun, D.R. Macfarlane, M. Forsyth, Ionic liquids as antiwear additives in base oils: influence of structure on miscibility and antiwear 
performance for steel on aluminium, ACS Appl. Mater. Interfaces 5 (2013) 11544-11553, 2 https://doi.org/10.1021/am4037614.

3 [14] J. Qu, P.J. Blau, S. Dai, H. Luo, H.M. Meyer, Ionic liquids as novel lubricants and additives 4 for diesel engine applications, Tribol. Lett. 35 (2009) 181-189, 5 https://doi.org/10.1007/s11249-009-9447-1.

6 [15] A. Hernández Battez, R. González, J.L. Viesca, A. Fernández-González, M. Hadfield, 7 Lubrication of PVD coatings with ethyl-dimethyl-2-methoxyethylammonium tris 8 (pentafluoroethyl) trifluorophosphate, Tribol. Int. $58 \quad$ (2013) 71-78, 9 https://doi.org/10.1016/j.triboint.2012.10.001.

10 [16] R. González, A.H. Battez, J.L. Viesca, A. Higuera-Garrido, A. Fernández-González, 11 Lubrication of DLC coatings with two tris(pentafluoroethyl)trifluorophosphate anion-based liquids, Tribol. Trans. $\quad 56$ 887-95, https://doi.org/10.1080/10402004.2013.810319.

[18] D. Blanco, R. González, A. Hernández Battez, J.L. Viesca, A. Fernández-González, Use of ethyl-dimethyl-2-methoxyethylammonium tris(pentafluoroethyl) trifluorophosphate as base oil additive in the lubrication of TiN PVD coating, Tribol. Int. 44 (2011) 645-650, https://doi.org/10.1016/j.triboint.2011.01.004.

[19] A. García, R. González, A. Hernández Battez, J.L. Viesca, R. Monge, A. FernándezGonzález, M. Hadfield, Ionic liquids as a neat lubricant applied to steel-steel contacts, Tribol. Int. 72 (2014) 42-50, https://doi.org/10.1016/j.triboint.2013.12.007.

[20] V. Totolin, I. Minami, C. Gabler, N. Dörr, Halogen-free borate ionic liquids as novel lubricants for tribological applications, Tribol. Int. 67 (2013) 191-198, https://doi.org/10.1016/j.triboint.2013.08.002.

[21] J.L. Viesca, A. García, A. Hernández Battez, R. González, R. Monge, A. FernándezGonzález, M. Hadfield, FAP- anion ionic liquids used in the lubrication of a steel steel contact, Tribol. Lett. 52 (2013) 431-437, https://doi.org/10.1007/s11249-013-0226-7. 
1 [22] I. Madanhire, C. Mbohwa, Mitigating Environmental Impact of Petroleum Lubricants,

$2 \quad$ Springer International Publishing, 2016.

3 [23] P. Oulego, J. Faes, R. González, J.L. Viesca, D. Blanco, A.H. Battez, Relationships between the physical properties and biodegradability and bacteria toxicity of fatty acid-based ionic liquids, Journal of Molecular Liquids, $292 \quad$ (2019) 111451, https://doi.org/10.1016/j.molliq.2019.111451

[24] R. Gusain, S. Dhingra, O. Khatri, Fatty-acid-constituted halogen-free ionic liquids as renewable friendly, and high-performance lubricant additives, Ind. Eng. Chem. Res. 55 (2016) 856-865, https://doi.org/10.1021/acs.iecr.5b03347

[25] A. Hernández Battez, N. Rivera, D. Blanco, P. Oulego, J.L. Viesca, R. González, Physicochemical, traction and tribofilm formation properties of three octanoate-, laurate- and palmitate-anion based ionic liquids, Journal of Molecular Liquids, 284 (2019) 639-646, https://doi.org/10.1016/j.molliq.2019.04.050

[26] R. Gusain, A. Khan, O.P. Khatri, Fatty acid-derived ionic liquids as renewable lubricant additives: Effect of chain length and unsaturation, Journal of Molecular Liquids 301 (2020) 112322, https://doi.org/10.1016/j.molliq.2019.112322

[27] A. Khan, R. Gusain, M. Sahai, O.P. Khatri, Fatty acids-derived protic ionic liquids as lubricant additive to synthetic lube base oil for enhancement of tribological properties, Journal of Molecular Liquids, 293 (2019) 111444, https://doi.org/10.1016/j.molliq.2019.111444

[28] D. Blanco, N. Rivera, P. Oulego, M. Díaz, R. González, A. Hernández Battez, Novel fatty acid anion-based ionic liquids: contact angle, surface tension, polarity fraction and spreading parameter, Journal of Molecular Liquids, $288 \quad$ (2019) 110995, https://doi.org/10.1016/j.molliq.2019.110995

[29] R. Gusain, S. Panda, P.S. Bakshi, R.L. Gardas, O.P. Khatri, Thermophysical properties of trioctylalkylammonium bis(salicylato) borate ionic liquids: Effect of alkyl chain length, 
1 Journal of $\quad$ Molecular $\quad$ Liquids 269

2 https://doi.org/10.1016/j.molliq.2018.08.083

3 [30] J. Yu, R.T. Wheelhouse, M.A. Honey, N. Karodia, Synthesis and characterisation of novel nopyl-derived phosphonium ionic liquids, Journal of Molecular Liquids 316 (2020) 113857, https://doi.org/10.1016/j.molliq.2020.113857

[31] M. Sernaglia, D. Blanco, A. Hernández Battez, J.L. Viesca, R. González, M. Bartolomé, Two fatty acid anion-based ionic liquids - part I: Physicochemical properties and tribological behavior as neat lubricants, Journal of Molecular Liquids, 305 (2020) 112827, https://doi.org/10.1016/j.molliq.2020.112827

[32] P.C. Jiao, Y. Zhang, W.L. Yuan, G.H. Tao, H.Q. Cai, Synthesis, structure and properties of water-free pentanitratoyttrate(III) ionic liquids, Journal of Molecular Structure, 1222 (2020 128953, https://doi.org/10.1016/j.molstruc.2020.128953

[33] P.J. Carvalho, S.P. Ventura, M.L. Batista, B. Schröder, F. Gonçalves, J. Esperança, F. Mutelet, J.A. Coutinho, Understanding the impact of the central atom on the ionic liquid behavior: phosphonium vs ammonium cations, J. Chem. Phys. 140 (2014) 064505, https://doi.org/10.1063/1.4864182

[34] K. Tsunashima, E. Niwa, S. Kodama, M. Sugiya, Y. Ono, Thermal and transport properties of ionic liquids based on benzyl-substituted phosphonium cations, J. Phys. Chem. 113 (2009) 15870-15874, https://doi.org/10.1021/jp908356c

[35] A. Khan, S.R. Yasa, R. Gusain, O.P. Khatri, Oil-miscible, halogen-free, and surface-active lauryl sulphate-derived ionic liquids for enhancement of tribological properties, Journal of Molecular Liquids (2020) In press, https://doi.org/10.1016/j.molliq.2020.114005 


\section{Supporting Information}

\section{1) Synthesis Procedure of the FAILS:}

In the following three steps the procedure of the synthesis of Methyltrioctylammonium hexanoate $([\mathrm{N} 8,8,8,1][\mathrm{C} 6: 0]), \quad$ methyltrioctylammonium stearate $\left(\left[\mathrm{N}_{8,8,8,1}\right]\left[\mathrm{C}_{18: 0}\right]\right)$ and methyltrioctylammonium oleate $\left(\left[\mathrm{N}_{8,8,8,1}\right]\left[\mathrm{C}_{18: 1}\right]\right)$ fatty acid derived ILs (FAILs), using a salt metathesis reaction, is indicated. As indicated in the manuscript, the procedure has already been previously described by the authors [25]:

i. Ester formation: $25 \mathrm{mmol}$ of sodium hydroxide in aqueous solution is added to $25 \mathrm{mmol}$ of the selected fatty acid dissolved in ethanol solution, leaving the solution under stirring at $800 \mathrm{rpm}$ for $12 \mathrm{~h}$. The expected product is an ester; the ethanol is removed by vacuum distillation in a rotary evaporator and then the water is eliminated in an oven at $65^{\circ} \mathrm{C}$, until the stoichiometric weight is obtained.

ii. Metathesis reaction: the ester is dissolved in aqueous medium and mixed with 25 mmol of methyltrioctylammonium bromide dissolved in toluene. The mixture is left under continuous stirring $(800 \mathrm{rpm}$ ) for $24 \mathrm{~h}$. The new FAIL obtained is purified from the reaction mixture by separation of the organic phase after several washes with ultrapure water.

iii. Elimination of solvent: the solvent will be finally eliminated by vacuum distillation in a rotary evaporator, obtaining the ionic liquid derived from the fatty acid.

\section{2) Confirmation of Molecular Structures:}

As indicated in the manuscript, the molecular structure of FAILs has been previously confirmed by the authors [28] by ${ }^{1} \mathrm{H}$ and ${ }^{13} \mathrm{C}$ NMR and FTIR. The NMR spectra were obtained with a Bruker serie Avance AV600 nuclear magnetic resonance spectrometer (NMR) using $\mathrm{CDCl}_{3}$ as the solvent. The NMR was operated with a $5 \mathrm{~mm}$ broad band probe at 600.15 and $150.92 \mathrm{MHz}$ resonance frequencies for ${ }^{1} \mathrm{H}$ and ${ }^{13} \mathrm{C}$ NMR, respectively. Tables $\mathrm{S} 1$ and $\mathrm{S} 2$ show the chemical shifts of ${ }^{1} \mathrm{H}$ $\mathrm{NMR}$ and ${ }^{13} \mathrm{C}$ NMR along with their assignments and the molecular structure of the ions. 
Table S1. Chemical shifts of ${ }^{1} \mathrm{H}$ NMR for the FAILs

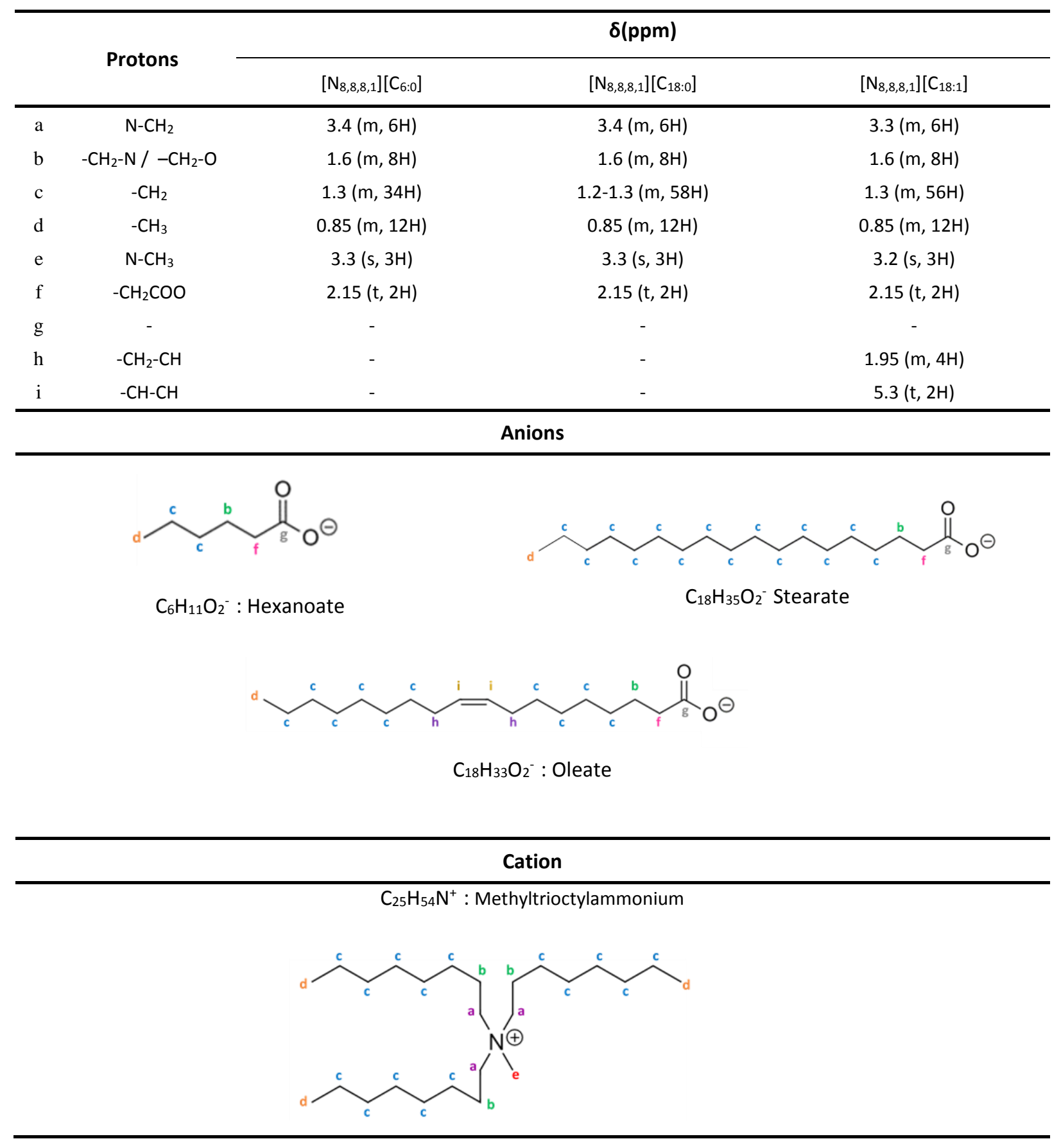


Table S2. Chemical shifts of ${ }^{13} \mathrm{C}$ NMR for the FAILs

\begin{tabular}{lcccc}
\hline & & \multicolumn{3}{c}{$\delta$ (ppm) } \\
\cline { 3 - 5 } & Carbon & {$\left[\mathrm{N}_{8,8,8,1}\right]\left[\mathrm{C}_{6: 0}\right]$} & {$\left[\mathrm{N}_{8,8,8,1}\right]\left[\mathrm{C}_{18: 0}\right]$} & {$\left[\mathrm{N}_{8,8,8,1}\right]\left[\mathrm{C}_{18: 1}\right]$} \\
\hline $\mathrm{n}$ & & $61.34(3 \mathrm{C})$ & $61.19(3 \mathrm{C})$ & $61.3(3 \mathrm{C})$ \\
$\mathrm{b}$ & $\mathrm{N}-\mathrm{CH}_{2}$ & $22.4(4 \mathrm{C})$ & $22.3(4 \mathrm{C})$ & $22.3(4 \mathrm{C})$ \\
$\mathrm{c}$ & $-\mathrm{CH}_{2}-\mathrm{N}-\mathrm{CH}_{2}-\mathrm{O}$ & $22.5-31.9(29 \mathrm{C})$ & $22.3-31.6(25 \mathrm{C})$ \\
$\mathrm{d}$ & $-\mathrm{CH}_{3}$ & $22.5-32.2(17 \mathrm{C})$ & $14-14.1(4 \mathrm{C})$ & $14-14.1(4 \mathrm{C})$ \\
$\mathrm{e}$ & $\mathrm{N}_{3}-\mathrm{CH}_{3}$ & $44-14.1(4 \mathrm{C})$ & $48.7(1 \mathrm{C})$ & $49(1 \mathrm{C})$ \\
$\mathrm{f}$ & $-\mathrm{CH}_{2} \mathrm{COO}$ & $48.8(1 \mathrm{C})$ & $38.84(1 \mathrm{C})$ & $38.9(1 \mathrm{C})$ \\
$\mathrm{g}$ & $-\mathrm{C}$ & $38.6(1 \mathrm{C})$ & $179.44(1 \mathrm{C})$ & $179.8(1 \mathrm{C})$ \\
$\mathrm{h}$ & $-\mathrm{CH}_{2}-\mathrm{CH}$ & $179.35(1 \mathrm{C})$ & - & $27.1-27.2(2 \mathrm{C})$ \\
$\mathrm{i}$ & $-\mathrm{CH}-\mathrm{CH}$ & - & - & $129.8-129.9(2 \mathrm{C})$ \\
\hline
\end{tabular}

The Fourier-transform infrared spectroscopy (FTIR) of the FAILs were obtained using a Varian 670-IR FTIR spectrometer with the following experimental setup: 16 scans, $4 \mathrm{~cm}^{-1}$ resolution and aperture open. Spectra were recorded between 600 and $4000 \mathrm{~cm}^{-1}$. Fig. S1 displays the FTIR spectra of the three FAILs.

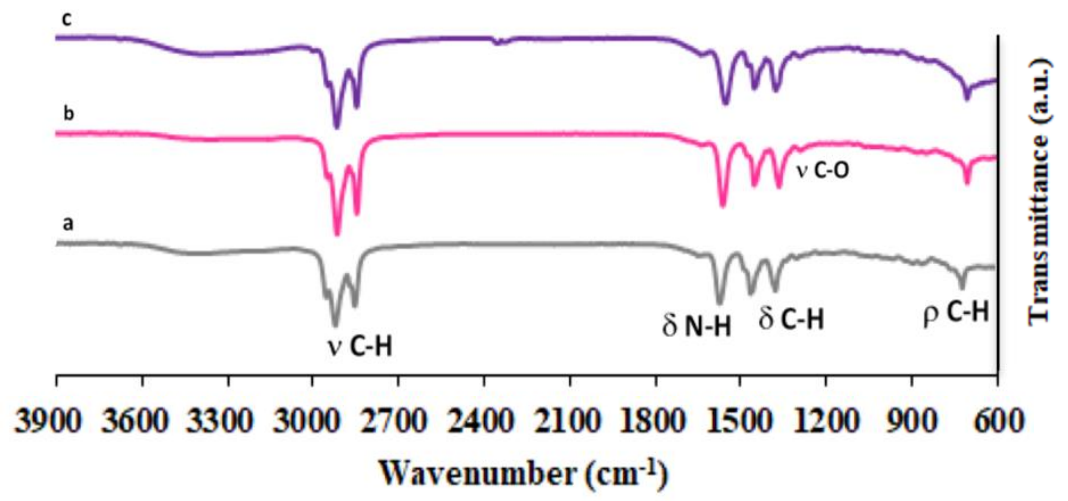

Fig. S1. FTIR spectra of the FAILs including assignments of the peaks: a) $\left[\mathrm{N}_{8,8,8,1}\right]\left[\mathrm{C}_{6: 0}\right]$, b) $\left[\mathrm{N}_{8,8,8,1}\right]\left[\mathrm{C}_{18: 0}\right]$ and $\left.\mathrm{c}\right)\left[\mathrm{N}_{8,8,8,1}\right]\left[\mathrm{C}_{18: 1}\right]$. 